\title{
POBREZA Y EMPLEO EN LA ESTRATEGIA EUROPA 2020
}

\author{
Poverty and Employment in the Europe 2020 Strategy
}

\author{
José A. Estévez Araújo \\ Universidad de Barcelona \\ jestevez@ub.edu
}

\section{Resumen:}

La Ilamada Estrategia Europa 2020 se marcó como objetivo sacar de la pobreza a 20 millones de personas durante la presente década, marcada por una fuerte crisis económica. Este propósito no sólo no se ha cumplido, sino que en el año 2016 la pobreza era todavía mayor que cuando se cuantificó la meta a alcanzar, aunque parece haber habido un cambio de tendencia en 2017. Las razones del fracaso de las políticas de lucha contra la pobreza en la UE son diversas, pero una de las más importantes es haber confiado excesivamente en el crecimiento económico y la creación de empleo como mecanismos para disminuir el número de personas pobres. Hoy en día el trabajo no constituye un seguro contra la pobreza debido a su precarización, como lo demuestra el hecho de que más de una décima parte de los trabajadores europeos sean pobres en el momento actual.

\section{Palabras clave:}

Pobreza, empleo, precarización, Unión Europea, Europa 2020.

\begin{abstract}
:
The so-called Europe 2020 Strategy was aimed at removing 20 million people from poverty during the present decade. This period has been characterized by a strong economic crisis in the EU. The purpose of the Strategy 2020 has not been fulfilled. In 2016, poverty was greater than in 2008 . There are several reasons for the failure of policies to combat poverty in the EU. One of the most important causes is to have considered economic growth and job creation as the only mechanisms to reduce the number of poor people. Today, work is not an insurance against poverty due to its precariousness: more than a tenth of European workers are poor at the present time.
\end{abstract}

\section{Keywords:}

Poverty, Employment, Precariousness, European Union, Europe 2020.

Recibido: 05/11/2018

Aceptado: 15/12/2018 


\section{SER POBRE EN LA UNIÓN EUROPEA}

La pobreza constituye una funesta realidad de formidables proporciones en el ámbito de la Unión Europea, aunque muchos habitantes de los eufemísticamente denominados "terceros países" vean "Europa" como un paraíso del bienestar. En aquella magnífica película de los noventa dirigida por Gianni Amelio y titulada L'América, los albaneses, que atravesaban la peor crisis de su historia contemporánea, tenían una imagen de Italia como el país opulento que mostraban la publicidad televisiva y los concursos de la cadena Tele 5, propiedad de Berlusconi, en los que los participantes ganaban premios fabulosos.

En 1991, el buque de carga Vlora, que regresaba de Cuba con un cargamento de azúcar, fue asaltado durante una escala en Durrës por una turba de personas desesperadas por el escenario de caos y miseria que reinaba en Albania. Su capitán se vio obligado a poner rumbo a Italia en un barco peligrosamente sobrecargado, cuyos motores deberían haber sido reparados durante el tiempo de atraque. Las inauditas fotografías del Vlora a su llegada a la ciudad italiana de Bari el 8 de agosto de 1991, inverosímilmente abarrotado por una compacta multitud de personas que se asemejaba a un enorme enjambre de abejas, forman parte de la galería de imágenes de nuestra memoria. No obstante, aquella odisea de los albaneses ha palidecido frente a las terribles experiencias de los desplazados sirios, que intentan llegar a una Europa que los transformó de refugiados en inmigrantes ilegales, literalmente de un día para otro.

En la Unión Europea hay 112.9 millones de personas pobres de acuerdo con los últimos datos disponibles en Eurostat, correspondientes al año 2017, cifra que representa el $22.5 \%$ del total de la población de la Unión ${ }^{1}$. En el lenguaje burocrático se utiliza la expresión "personas en riesgo de pobreza o exclusión social" (AROPE: At Risk Of Poverty or social Exclusion) para referirse a ese colectivo que representa casi una cuarta parte de la población europea. Pero los diferentes indicadores que se utilizan para determinar quiénes se encuentran en esa situación de "riesgo" permiten afirmar que la gran mayoría de esas personas no están en peligro de ser pobres, sino que ya lo son de hecho.

El nivel de ingresos es la medida que se ha usado con mayor frecuencia para definir la pobreza y la que intuitivamente resulta más comprensible a la generalidad de los ciudadanos, pues saben por experiencia propia la cantidad de dinero que necesitan ganar al mes para poder vivir. El indicador AROPE relativo al nivel de renta fija el umbral del riesgo de pobreza en las personas cuyos ingresos por unidad de consumo son inferiores al $60 \%$ de la renta mediana disponible equivalente (después de transferencias sociales). La renta mediana por unidad de consumo se define como los ingresos netos de cada hogar divididos entre el número de sus unidades de consumo, calculadas de acuerdo con una escala que da un peso de 1 al primer adulto, 0,5 al segundo y siguientes y 0,3 a los menores de 14 años.

En el caso de España, la mediana de ingresos de la población por unidad de consumo era, en 2017, de 14.203€, por lo que el umbral AROPE se situaba en 8.522

\footnotetext{
${ }^{1}$ Todos los datos que se manejan en este texto han sido extraídos de Eurostat.
} 
euros anuales. Esta cifra se traduce en que una pareja con dos hijos menores de catorce años está "en riesgo" de ser pobre si percibe menos de 18.407€ anuales (8.522 $+4.261+2.812+2.812$ ), que equivalen a una renta de unos 1.500 euros al mes. Ese nivel de ingresos puede generar situaciones muy diferentes, pues no están en las mismas circunstancias una familia con una vivienda propia y la hipoteca ya pagada que viva en Palencia (la ciudad más barata de España) que otra que viva de alquiler en Barcelona (la más cara), donde encontrar un piso de 3 habitaciones por menos de 900 euros al mes resulta prácticamente imposible. Dejando de lado esos dos casos extremos, la situación normal de una pareja con dos niños es que tendrán que dedicar una parte de sus ingresos a pagar la vivienda, sea en concepto de hipoteca o de alquiler. Partiendo de la hipótesis de que ese gasto suponga unos 500 euros al mes, restan otros mil para mantener a toda la familia, es decir, para hacer la compra, pagar los suministros, adquirir ropa, libros o material escolar y pagar el transporte. Decir que esa familia se encuentra en una situación de "riesgo" de pobreza es encubrir que los padres sólo pueden llegar a fin de mes si no tienen que afrontar gasto imprevisto alguno.

El carácter eufemístico de la expresión "en riesgo de pobreza" resulta aún más claro en el caso de otro de los indicadores utilizados: el de las personas que viven en hogares con una intensidad de empleo "muy baja", considerándose tal la que está por debajo del $20 \%$ del total del potencial de trabajo ${ }^{2}$. En el caso de nuestra familia con dos hijos eso podría traducirse en una situación en que sólo uno de los padres tuviera un trabajo a tiempo parcial de menos de 16 horas semanales de promedio. El progenitor con empleo debería cobrar entre 25 y 30 euros la hora para que su familia pudiese vivir con dignidad en el mejor de los supuestos posibles: que trabajase 15 horas semanales. En casos menos favorables, resulta difícil imaginar que esa familia estuviese únicamente "en riesgo" de ser pobre, sin serlo realmente.

En caso de cumplir dos o tres indicadores AROPE, las personas se contabilizan sólo una vez, por lo que es de suponer que los hogares con baja intensidad de empleo también estarán por debajo del umbral basado en el nivel de ingresos. En el caso español, el porcentaje de personas que viven en hogares con baja intensidad de empleo casi se ha duplicado entre 2007 y 2017 pasando de 6,6 a 12,8 y es el

\footnotetext{
${ }^{2}$ El tercer indicador de pobreza es el de privación material severa. Esa situación consiste en vivir en un hogar que sufre al menos cuatro de las siguientes carencias:

1) No puede permitirse ir de vacaciones al menos una semana al año.

2) No puede permitirse una comida de carne, pollo o pescado al menos cada dos días.

3) No puede permitirse mantener la vivienda con una temperatura adecuada.

4) No tiene capacidad para afrontar gastos imprevistos (de 650 euros).

5) Ha tenido retrasos en el pago de gastos relacionados con la vivienda principal (hipoteca o alquiler, recibos de gas, comunidad...) o en compras a plazos en los últimos 12 meses.

6) No puede permitirse disponer de un automóvil.

7) No puede permitirse disponer de teléfono.

8) No puede permitirse disponer de un televisor.

9) No puede permitirse disponer de una lavadora.
} 
indicador que más ha crecido, a pesar de que no incluye a las personas de 60 años o más.

En algunos textos se habla de "pobreza relativa" y "pobreza severa" en lugar de "en riesgo". Según el indicador de ingresos, estarían en situación de pobreza severa quienes vivieran en hogares que tuvieran un rédito inferior al $30 \%$ de la renta mediana por unidad de consumo lo que, en el caso de la España de 2017, se traduciría en 4.261€. Nuestra familia de referencia, compuesta por una pareja y dos hijos pequeños, estaría en situación de pobreza severa si tuviese unos ingresos de $9.203 €$ al año, lo que equivale a una renta de unos 750 euros al mes, la mitad que la del umbral del AROPE. El 7\% de la población española se encuentra en esta situación extrema, pero a efectos estadísticos son personas "en riesgo de pobreza".

\section{LA LUCHA CONTRA LA POBREZA EN LA UNIÓN EUROPEA}

Las primeras decisiones que se adoptaron a nivel europeo en materia de pobreza y exclusión social se remontan a los años setenta, debido a que las crisis de esa década acrecentaron el número de desempleados. La tasa de pobreza se incrementó constantemente hasta fin de siglo y en la Estrategia de Lisboa (2000) se calificó de "inaceptable" esa situación. Sin embargo, la preocupación de las instituciones europeas por las personas indigentes no acarreó que asumieran competencias en materia de política social, reiterándose en la mencionada estrategia que la lucha contra la pobreza era tarea de los estados. Únicamente se introdujo un nuevo mecanismo, el Ilamado Método Abierto de Coordinación (MAC), que debía servir para coordinar las políticas de los estados entre sí y con los objetivos que fijase el Consejo. Pero la participación en este dispositivo tenía carácter voluntario y el MAC utilizaba únicamente mecanismos de soft law, es decir, no coercitivos.

La Estrategia Europa 2020, fue aprobada en 2010 y configura la arquitectura actualmente vigente en la Unión Europea, cuyo mecanismo vertebrador es el Ilamado "Semestre Europeo". Los planes para la presente década están distribuidos en tres pilares: la coordinación temática, la supervisión macroeconómica y la vigilancia fiscal. La ordenación de la política social está contenida en el primero de ellos y Europa 2020 señala como uno de sus objetivos sacar a 20 millones de personas del "riesgo de pobreza o exclusión social".

Esas miras resultan bastante modestas frente a una realidad en la que 112 millones de personas son pobres (113 si incluimos Croacia), según las estimaciones hechas para el año 2017 y de 116 millones en 2008, que fue la fecha de referencia elegida para cuantificar el objetivo. Cada estado de la UE se ha fijado un objetivo de reducción de sus cifras de pobreza durante la presente década que, en el caso español es de un millón y medio de personas.

La lucha europea contra la pobreza se basa en el "crecimiento inclusivo", lo que significa que sus políticas en este campo se centran en la entrada o vuelta al mercado laboral: el crecimiento económico generará puestos de trabajo que permitirán a las personas pobres salir de la miseria. Aunque la Unión Europea ha venido trabajando tradicionalmente con una concepción multidimensional de la pobreza, la consideración de que el empleo es el único remedio para dejar de ser pobre es estric- 
tamente unidimensional. La práctica de la presente década pone de manifiesto que para la UE lo prioritario, o, incluso, lo único necesario para luchar contra la pobreza ha sido incrementar el PIB y, con él, el empleo ${ }^{3}$.

Los datos disponibles en Eurostat ponen de manifiesto que un incremento del PIB no disminuye inmediatamente los índices de pobreza. Existe un desfase entre el crecimiento económico y la mengua del número de pobres. En el supuesto inverso, la divergencia es mucho menor: las situaciones de crisis económica generan muy rápidamente un incremento de la pobreza. Así, en el caso de España, el PIB per cápita alcanzó su punto más bajo en 2013 y empezó a ascender a partir de 2014. Sin embargo, el porcentaje de personas pobres aumentó dos puntos en 2014 respecto a 2013, alcanzando el nivel más alto desde el inicio de la crisis (29,2\%). Durante los años 2015-2016, la tasa de pobreza siguió siendo superior a la de 2013, habiendo tenido que esperar hasta 2017 para que se situase por debajo. Sin embargo, el porcentaje de pobres existente en nuestro país el año 2017 era todavía superior al del 2008 (la fecha de referencia), a pesar de que el PIB per cápita se situaba ya por encima del de ese año.

En el conjunto de la UE, el PIB per cápita bajó de $26.100 €$ en 2008 a $24.500 €$ en 2009. El porcentaje de personas pobres empezó a subir en 2010 y siguió siendo más alto que en 2008 hasta 2016. Sin embargo, el PIB per cápita llegó a los niveles de 2008 en 2011 y ha seguido aumentando desde entonces.

En el caso de Italia, el PIB per cápita alcanzó la cuantía del de 2008 solamente en 2016. Sin embargo, ese año se registró el mayor índice de pobreza del periodo (30\%) y en 2017 el porcentaje de personas pobres supera en tres puntos al de 2008. En un país escandinavo como Dinamarca, la pobreza ha ido oscilando entre un 17 y un $18 \%$ entre 2009 y 2017 , cuando era de 16,3 en 2008. El PIB ha aumentado continuadamente desde 2010, alcanzando los niveles de 2008 en 2011. Sin embargo, ese incremento no se ha traducido en una disminución continuada de la tasa de pobreza, sino en diversas oscilaciones de la misma, sin correlación con la evolución del PIB. El porcentaje actual de daneses pobres sigue siendo superior al de 2008.

La próspera Alemania es un ejemplo patente de la falta de sincronía entre crecimiento y disminución de la pobreza. En ese país, el único año en que disminuyó

\footnotetext{
3 Incluso documentos vinculados a la Estrategia Europa 2020 reflejan esta visión multidimensional de la pobreza, que no se ha traducido en una práctica acorde con la misma. Así, en la COMUNICACIÓN de la Comisión al Parlamento Europeo, al Consejo, al Comité Económico y Social Europeo y al Comité de las Regiones, del año 2010, titulada "La Plataforma Europea contra la Pobreza y la Exclusión Social: Un marco europeo para la cohesión social y territorial", se señala la necesidad de utilizar "... planteamientos que engloben todos los ámbitos de actuación, y ello requiere que el reto de combatir la pobreza se integre en el diseño de todas las políticas. Exige asimismo una coordinación mejor entre las políticas macroeconómicas y microeconómicas y pone de relieve el papel fundamental de una serie de ámbitos de actuación que rebasan los límites tradicionales de las políticas de inclusión y protección social: será esencial establecer sinergias eficaces con otras iniciativas emblemáticas de Europa 2020.
} 
el PIB per cápita fue 2009 (unos 1.000 euros). En 2010 el PIB per cápita volvió a crecer, superando al alcanzado en 2008 y ha seguido incrementándose hasta hoy. Sin embargo, los índices de pobreza no han cambiado significativamente durante el periodo 2008-2016, pues se han mantenido en torno al 20\%. Sólo han descendido al $19 \%$ en 2017. Se trata de una tasa bastante elevada si la comparamos con la de los países nórdicos, con la de Holanda (aunque en este país la tasa de pobreza no ha parado de crecer) o, incluso, con la de Francia.

Esta diferencia de timing entre, por un lado, el estallido de la crisis y el incremento de la tasa de pobreza, y, por otro, el crecimiento económico y la disminución del porcentaje de personas pobres se debe fundamentalmente a dos razones. La primera es que la globalización neoliberal ha traído consigo una profunda traslación de los riesgos socioeconómicos. Muchos peligros que antes asumían las empresas se han transferido a los trabajadores por medio del desmantelamiento del modelo de relaciones laborales propio del llamado "estado del bienestar". La "flexibilización" del mercado de trabajo ha dado lugar al nacimiento del "precariado", integrado por trabajadores temporales, a tiempo parcial, empleados fijos pero desprotegidos frente al despido y falsos autónomos. Esta configuración de las relaciones laborales permite que las empresas hagan recaer sobre los trabajadores los costes que acarrea una coyuntura desfavorable, bien despidiéndolos, bien rescindiendo las subcontratas o bien disminuyendo sus salarios.

La segunda razón de la falta de sincronía es el incremento de la desigualdad que la globalización ha traído consigo: el crecimiento del PIB no se traduce rápidamente en una disminución de la pobreza porque el aumento de la riqueza no se distribuye equitativamente. En las últimas décadas, el porcentaje de participación de los salarios en las rentas totales ha disminuido radicalmente, mientras que los dividendos y las rentas de los productos financieros han aumentado su fracción. Ya no se da aquel fenómeno de la época keynesiana en el que el crecimiento del "pastel" significaba un aumento del pedazo que correspondía a todos, aunque las proporciones entre las diversas porciones se mantuvieran estables. Tampoco las crisis disminuyen las porciones de todos en igual medida, sino que los mayores costes recaen en los más desfavorecidos.

Hay algunos indicadores que permiten verificar quiénes han sufrido con mayor dureza las consecuencias de la crisis. Así, el riesgo de pobreza del quintil más pobre de la población de la UE ha pasado del 85,1 \% en 2009 a estar en torno al 87\% desde 2011 a 2016. En España ha sido del 100\% durante todo ese periodo y ha seguido siendo así en el año 2017. En Italia pasó del 94\% al 100\% en 2016 y ahí se mantiene. El segundo quintil de europeos en nivel de renta pasó de una tasa de pobreza de 16,4 en 2008 a un máximo de 19,3 en 2014, disminuyendo desde entonces hasta un porcentaje estimado del 14,5 en 2017. En España dio un enorme salto desde el 9\% en 2008 al $28 \%$ en 2014, lo que denota la intensidad con que la crisis afectó a los sectores de la población con menos renta.

Otro dato significativo que refleja el reparto de los costes de la crisis y de los beneficios de la recuperación económica es la evolución del coeficiente de Gini en los países de la Unión Europea durante el periodo 2008-2017. Este indicador mide el grado de desigualdad existente entre los habitantes de un determinado territorio en 
una escala que va del 0 (igualdad absoluta) al 100 (máxima desigualdad posible). El índice Gini aumentó en España durante este periodo pasando del 32,4 en 2008 a un máximo de 34,7 en 2014, el año con mayor índice de pobreza en nuestro país. En la UE el coeficiente se ha mantenido estable en torno al 31\%, Pero paradójicamente donde ha aumentado más significativamente la desigualdad ha sido en los países nórdicos, con la excepción de Finlandia.

Pero las cifras que reflejan de modo más elocuente el incremento de la "injusticia distributiva" corresponden a la evolución de la ratio de quintiles de renta 20/80, que se define como la relación entre el ingreso total recibido por el $20 \%$ de la población con el ingreso más alto (el quintil superior) y la recibida por el $20 \%$ de la población con el ingreso más bajo (el quintil inferior). Esta ratio ha aumentado constantemente en España pasando de 5,6 en 2008 a 6,9 en 2015, lo que quiere decir que el 20\% más rico de la población ha pasado de percibir una cantidad equivalente a 5,6 veces la renta total del quintil más pobre a cobrar casi 7 veces más. En 2017 esa proporción se sitúa en 6,6. En la UE la ratio en 2008 era del 5,0 y no ha variado sustancialmente durante el periodo. Los únicos países que han superado la ratio española de 6,9 han sido Rumanía, Bulgaria y Lituania, por lo que España se revela como el país con mayor desigualdad de renta de la Europa occidental. Durante el periodo de referencia, el $10 \%$ más pobre ha visto disminuir su participación en la renta en un $17 \%$, mientras que esta proporción se ha incrementado en un $5 \%$ para el $10 \%$ más rico y en un $9 \%$ para el $1 \%$ más acaudalado. ${ }^{4}$

\section{LOS TRABAJADORES POBRES}

A diferencia de la Estrategia de Lisboa, que fue lanzada coincidiendo con el cambio de siglo, en Europa 2020 no se hace referencia a la calidad del empleo sino sólo a su productividad. Por su parte, las políticas de empleo en la mayoría de los países UE se han centrado en la "flexibilidad", aunque en ocasiones la hayan vestido de "flexiguridad". La multiplicación del trabajo precario y la disminución de los salarios ha incrementado las cifras de trabajadores pobres en la UE. Tener o conseguir un empleo no es ya un seguro para salvarse de la pobreza en Europa, como lo demuestra el hecho de que en 2017 haya un 12,3\% de trabajadores pobres en la Unión, cifra que alcanzó el 13,4\% el año 2012.

La situación de los diferentes países es muy dispar en el caso de esta variable como ocurre con todas las demás. En España, el porcentaje de working poors asciende al $15 \%$ y en Italia alcanza el $17 \%$. Más del $20 \%$ de los asalariados están en situación de pobreza en Grecia (22,7 y subiendo) o Rumanía (26,2\% con un pico del 37,5 en

\footnotetext{
${ }^{4}$ Curiosamente, los países más igualitarios de Europa no son los nórdicos (con la excepción de Finlandia), sino Eslovaquia, Eslovenia y la República Checa (con una ratio en torno al 3,5). Noruega tenía una ratio de 3,2 en 2012, pero en 2017 pasó a ser de 3,9, una de las consecuencias de la bajada de los precios del petróleo a partir de 2015. Suecia ha pasado del 3,7 en 2008 al 4,3 en 2017. Dinamarca incrementó la ratio del 3,6 en 2008 al 4,6 en 2009, que fue la mayor oscilación registrada en un año en Europa siendo inversamente proporcional al desplome del PIB, que ese mismo año se redujo casi un $5 \%$.
} 
2012). Finlandia tiene la tasa más baja de trabajadores pobres (3,5\%). El trabajo sí parece marcar la diferencia en el caso de Alemania, pues ese país tiene, como se ha visto, una alta tasa de personas en situación de pobreza (20\%), pero un porcentaje relativamente bajo de trabajadores pobres: un 9,5\%, habiendo alcanzado un pico de 11,2 en 2014, un año en que el porcentaje en la UE subió hasta el $13 \%$. Estas particularidades pueden explicar por qué fueron las personas incluidas en el primer quintil las que sufrieron con mayor dureza las consecuencias de la crisis en el país germano.

La Comisión Europea ha manifestado en diversas ocasiones su preocupación por el fenómeno de los trabajadores pobres. En la COMUNICACIÓN de la Comisión al Parlamento Europeo, al Consejo, al Comité Económico y Social Europeo y al Comité de las Regiones, del año 2010, titulada "La Plataforma Europea contra la Pobreza y la Exclusión Social: Un marco europeo para la cohesión social y territorial", ya mencionada en la nota 3, el órgano ejecutivo comunitario señaló: "[...] Desde 2000 ha aumentado el número de personas que padecen esta pobreza con empleo, como consecuencia del incremento del trabajo temporal y a tiempo parcial (incluido el trabajo a tiempo parcial involuntario), unido a veces al estancamiento de los salarios". Pero a pesar de esta "preocupación" la Unión no ha adoptado medidas decididas que promovieran la creación de empleos dignos.

Aunque el paro y la pobreza son producto de causas socioeconómicas están siendo presentadas, cada vez con mayor insistencia, como producto de la incapacidad de las personas para adaptarse a las exigencias del mercado. Por ello, las medidas a adoptar deben centrarse en mejorar su "empleabilidad". Esta filosofía, convierte a las personas en culpables de una situación de pobreza de la que no son responsables.

La idea de que los pobres son los causantes de su situación de miseria se gestó en los Estados Unidos de Reagan. La pobreza pasó de ser considerada un problema social a ser vista como una consecuencia de las deficiencias morales de quienes la padecían: de su falta de iniciativa, de su incapacidad de esforzarse, de su tendencia al parasitismo, de sus vicios... Por ello se adoptó la solución de dejar de subsidiar a los pobres para pasar a meterlos en la cárcel. Como resultado, de acuerdo con los últimos datos disponibles en el Bureau of Justice Statistics correspondientes al año 2016 (que pueden consultarse libremente por Internet), en Estados Unidos hay 6,613,500 personas sometidas a alguna forma de privación de libertad: encarceladas, en libertad condicional o en libertad bajo palabra.

El Ilamado "Workfare" fue otro de los efectos de la culpabilización de los estadounidenses pobres: los que siguieron recibiendo ayudas sociales quedaron sujetos a la obligación de buscar trabajo para seguir percibiendo esos ingresos. Sin embargo, para las personas mayores o las madres de familias monoparentales la obtención de un empleo no es una opción viable para salir de la pobreza. Los perceptores de ayudas fueron también sometidos a formas de control de su conducta para prevenir "malos hábitos" (como beber alcohol), lo que les situó en una posición equivalente a la de los reclusos en libertad condicional. En el lenguaje europeo el Workfare es denominado "inclusión activa", y consiste tambiénen someter a los perceptores de ayudas sociales a la obligación de buscar activamente trabajo y a aumentar su "empleabilidad" mediante cursos de capacitación. 
La insuficiencia de las políticas de crecimiento cuantitativo del empleo como mecanismo de lucha contra la pobreza queda también en evidencia por el número de personas que dependen de las transferencias sociales en la UE: un 10\% de la población europea percibe prestaciones diferentes de las pensiones de jubilación. Esa cifra equivale a la mitad de quienes cobran las pensiones de jubilación. Se trata, pues, en total, de un $30 \%$ de los habitantes de la UE.

El porcentaje de personas pobres ha aumentado en ambos colectivos. Un 18\% de las personas mayores de 65 años están en situación de pobreza actualmente en la Unión Europea. Este es el único parámetro que el autor de estas líneas ha encontrado en el que España está en una situación mejor que la media europea $(16,4 \%)$. La situación de los ancianos es tan preocupante como el dato de que una cuarta parte de los menores de 18 años son pobres. La cifra sube al 32\% en Italia y al $31 \%$ en España.

Los datos reseñados acerca de las transferencias sociales abundan en la demostración de la insuficiencia de una estrategia de lucha contra la pobreza centrada fundamentalmente en la creación de empleo que, además, carece de las garantías necesarias para ser digno. Una política laboral dirigida a incentivar la búsqueda de empleo entre las personas que viven en hogares con baja intensidad de trabajo puede tener, incluso, un efecto contraproducente: cabe la posibilidad de que disminuya sus ingresos si las familias canjean los subsidios públicos por trabajos precarios o mal pagados.

\section{CONCLUSIONES}

La lucha contra la pobreza en el marco de la Estrategia Europa 2020 no ha sido eficaz. El objetivo de salvar a 20 millones de personas del riesgo de pobreza y exclusión social no sólo no se ha ido alcanzando, sino que en 2012 llegó a haber casi seis millones y medio más de personas indigentes que en 2008. En el año 2016 todavía se contabilizaban ochocientos mil pobres más que ocho años antes. La tasa de pobreza parece que ha empezado a ser menor en 2017 que en 2008, pero las cifras que proporcionan las instituciones europeas deben ser contempladas con ciertas reservas.

Una razón fundamental de este fracaso hay que buscarla en la visión unilateral de las causas de la pobreza sustentada por los organismos europeos, que ha llevado a considerar la inserción en el mercado laboral como la condición necesaria y suficiente para dejar de ser pobre. Centrarse exclusivamente en el empleo como mecanismo para combatir la pobreza plantea, como se ha visto, una serie de graves problemas. El primero es que se han incentivado medidas de "flexibilización" del mercado de trabajo, que han puesto sobradamente de manifiesto su ineficacia para crear empleo de calidad. El segundo es que el incremento de la precariedad laboral ha permitido llevar a cabo una distribución tremendamente injusta de los costes de la crisis, por un lado, y de los beneficios de la recuperación económica, por otro. El balance general que puede hacerse de los resultados de la Estrategia Europa 2020 para reducir el número de personas pobres puede formularse así: el empleo ha dejado de ser un seguro contra la pobreza y las agudas oscilaciones de la economía durante el periodo 2008-2016 han dado lugar a una redistribución de la riqueza en favor de los más privilegiados.

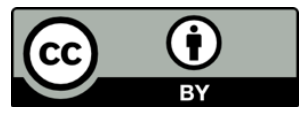

OXÍMORA REVISTA INTERNACIONAL DE ÉTICA Y POLÍTICA NÚM. 14. ENE-JUN 2019. ISSN 2014-7708. PP. 1-9 doi: 10.1344/oxi.2019.i14.27312 